\title{
Métodos de extração de inibidor de protease de sementes de Albizia niopoides
}

\author{
Flávia C.P. Tonelli1 ${ }^{*}$, Nilson M. C. Júnior²; Adriano G. Parreira. ${ }^{2}$, Daniel \\ B. Gonçalves²; José A. da Silva², Paulo A. Granjeiro² \\ ${ }^{1}$ Curso de Farmácia, Universidade Federal de São João Del-Rei, Divinópolis/MG \\ ${ }^{2}$ Curso de Bioquímica, Universidade Federal de São João Del-Rei, Divinópolis/MG \\ *e-mail: flacristinaptonelli@gmail.com
}

\section{Resumo}

Inibidores de protease (IP) são proteínas de reserva produzidos por plantas para oferecer proteção contra predadores ou infecção por patógenos. Eles são amplamente distribuídos no reino vegetal. Relatos na literatura apontam aplicação na fisiologia humana, participando de processos regulatórios como na coagulação sanguínea, inflamação e proliferação celular. Sementes de Albizia niopoides, originária do Havaí e das Américas, são ricas em proteínas de reserva. O presente trabalho teve como objetivo padronizar as melhores condições para extração de IPs de sementes de A. niopoides, considerando diferentes soluções $(\mathrm{NaCl} 0,15 \mathrm{M}$ e $0,30 \mathrm{M}, \mathrm{NaOH} 0,01 \mathrm{M}$ e $0,02 \mathrm{M}$, e água), tempos de extração $(1,2,3$, 4 e 5 horas $)$, temperaturas $\left(25^{\circ} \mathrm{C}, 37^{\circ} \mathrm{C}, 40^{\circ} \mathrm{C}, 50^{\circ} \mathrm{C}\right.$, $60^{\circ} \mathrm{C}, 70^{\circ} \mathrm{C}, 80^{\circ} \mathrm{C}, 90^{\circ} \mathrm{C}$ e $100^{\circ} \mathrm{C}$ ) e precipitação por sulfato de amônio (concentrações de 0-30\%, 30-60\% e 60-90\%). Para o teste das diferentes soluções, as sementes trituradas de A. niopoides $(1: 7 \mathrm{~m} / \mathrm{V})$ foram extraídas por $1 \mathrm{~h}$ à $25^{\circ} \mathrm{C}$. Para o teste de tempo, utilizou-se o melhor solvente de extração, por $1 \mathrm{~h}$ à $25^{\circ} \mathrm{C}$. Para o teste de temperatura, após a extração sob as mesmas condições, os extratos foram submetidos às diferentes temperaturas em banhomaria. Os testes de inibição foram posteriores a cada extração e utilizou-se tripsina, benzoil arginina $\rho$-nitroanilida (BAPNA), tampão Tris- $\mathrm{HCl}(\mathrm{pH} \mathrm{8,0).}$ Quantificou-se então as unidades inibitórias (UI) de cada amostra. Para quantificação de proteínas totais (PT) utilizou-se o método de Bradford, utilizando solução padrão de albumina (BSA). Calculou-se também a atividade específica (AE): razão de UI e PT. Conclui-se que o melhor solvente de extração 
foi o $\mathrm{NaCl} 0,3 \mathrm{M}$, no tempo de $5 \mathrm{~h}$, na temperatura de $25^{\circ} \mathrm{C}$ e o precipitado III (60-90\%) com a melhor AE. Com essa proposta metodológica as etapas seguintes para o sucesso da purificação total do IP terão a maior relação inibidor/proteínas totais.

Palavras-chave: inibidor de protease, Albizia niopoides, extração, sementes. 